\title{
German Francisella tularensis isolates from European brown hares (Lepus europaeus) reveal genetic and phenotypic diversity
}

Wolfgang Müller ${ }^{1}$, Helmut Hotzel ${ }^{1}$, Peter Otto ${ }^{1}$, Axel Karger ${ }^{2}$, Barbara Bettin ${ }^{2}$, Herbert Bocklisch ${ }^{3}$, Silke Braune ${ }^{4}$, Ulrich Eskens ${ }^{5}$, Stefan Hörmansdorfer ${ }^{6}$, Regina Konrad $^{6}$, Anne Nesseler $^{5}$, Martin Peters $^{7}$, Martin Runge ${ }^{4}$, Gernot Schmoock ${ }^{1}$ Bernd-Andreas Schwarz ${ }^{8}$, Reinhard Sting ${ }^{9}$, Kerstin Myrtennäs $^{10}$, Edvin Karlsson $^{10}$, Mats Forsman ${ }^{10}$ and Herbert Tomaso ${ }^{1 *}$

\begin{abstract}
Background: Tularemia is a zoonotic disease caused by Francisella tularensis that has been found in many different vertebrates. In Germany most human infections are caused by contact with infected European brown hares (Lepus europaeus). The aim of this study was to elucidate the epidemiology of tularemia in hares using phenotypic and genotypic characteristics of $F$. tularensis.

Results: Cultivation of $F$. tularensis subsp. holarctica bacteria from organ material was successful in 31 of 52 hares that had a positive PCR result targeting the Ft-M19 locus. 17 isolates were sensitive to erythromycin and 14 were resistant. Analysis of VNTR loci (Ft-M3, Ft-M6 and Ft-M24), INDELs (Ftind33, Ftind38, Ftind49, RD23) and SNPs (B.17, B.18, B.19, and B.20) was shown to be useful to investigate the genetic relatedness of Francisella strains in this set of strains. The 14 erythromycin resistant isolates were assigned to clade B.I, and 16 erythromycin sensitive isolates to clade B.IV and one isolate was found to belong to clade B.II. MALDI-TOF mass spectrometry (MS) was useful to discriminate strains to the subspecies level.

Conclusions: $F$. tularensis seems to be a re-emerging pathogen in Germany. The pathogen can easily be identified using PCR assays. Isolates can also be identified within one hour using MALDI-TOF MS in laboratories where specific PCR assays are not established. Further analysis of strains requires genotyping tools. The results from this study indicate a geographical segregation of the phylogenetic clade B.I and B.IV, where B.I strains localize primarily within eastern Germany and B.IV strains within western Germany. This phylogeographical pattern coincides with the distribution of biovar I (erythromycin sensitive) and biovar II (erythromycin resistance) strains. When time and costs are limiting parameters small numbers of isolates can be analysed using PCR assays combined with DNA sequencing with a focus on genetic loci that are most likely discriminatory among strains found in a specific area. In perspective, whole genome data will have to be investigated especially when terrorist attack strains need to be tracked to their genetic and geographical sources.
\end{abstract}

\footnotetext{
* Correspondence: herbert.tomaso@fli.bund.de

${ }^{1}$ Institute of Bacterial Infections and Zoonoses, Friedrich-Loeffler-Institut (Federal Research Institute for Animal Health), Naumburger Str. 96A, Jena D-07743, Germany

Full list of author information is available at the end of the article
} 


\section{Background}

Tularemia is a rare zoonotic disease caused by Francisella tularensis, a Gram negative, facultative intracellular, fastidious bacterium [1]. Most infections in animals and humans are caused by two $F$. tularensis subspecies, $F$. tularensis subsp. tularensis (Jellison type A) and $F$. tularensis subsp. holarctica (Jellison type B). F. tularensis type $A$ is endemic in North America and type B is located in Europe, Asia, and North America [2-4]. Three biotypes of the less virulent type $\mathrm{B}$ have been described: biovar I (erythromycin sensitive), biovar II (erythromycin resistant), and biovar japonica which can ferment glycerol [4].

In Germany, human infections are usually caused by skinning, preparing or eating infected hares or drinking contaminated water. F. tularensis was sporadically diagnosed in humans in the first half of the 20th century in Germany but almost disappeared in the following decades [5,6]. Between 1983 and 1992 only four sporadic cases of tularemia were notified in hares or rabbits from Lower Saxony, Rhineland-Palatinate, North Rhine-Westphalia and Baden-Württemberg, respectively [6]. After years without reported cases in animals the re-emergence of tularemia started in 2004 with an outbreak of tularemia in a semi-free living group of marmosets (Callithrix jacchus) in Lower Saxony [7], and in December 2005 an outbreak with 15 human cases due to contact with infected hares was reported from Hesse [8]. The detection of F. tularensis subsp. holarctica in organ samples of these hares using PCR assays was the beginning of our investigations of tularemia in European brown hares (Lepus europaeus) in Germany.

A variety of PCR methods has been established for the detection of F. tularensis DNA in both clinical and environmental specimens [9-11]. Farlow et al. developed a typing assay based on the variable-number of tandem repeats (VNTRs) [12] and Johansson et al. also described a twenty-five VNTR marker typing system that was used to determine the worldwide genetic relationship among $F$. tularensis isolates [1]. Byström et al. selected six of these 25 markers that were highly discriminatory in a study of tularemia in Denmark [13]. Vogler et al. [14] investigated the phylogeography of $F$. tularensis in an extensive study based on whole-genome single nucleotide polymorphism (SNP) analysis. From almost 30,000 SNPs identified among 13 whole genomes 23 clade- and subclade-specific canonical SNPs were identified and used to genotype 496 isolates. This study was expanded upon in another study that used a combination of insertion/deletions (INDELs) and single nucleotide polymorphism analysis [15].

The aim of this study was to elucidate the molecular epidemiology of $F$. tularensis in European brown hares in Germany between 2005 and 2010. Several previously published typing markers were selected and combined in a pragmatic approach to test whether they are suitable to elucidate the spread of tularemia in Germany. This included cultivation, susceptibility testing to erythromycin, a PCR assay for subspecies differentiation detecting a 30 bp deletion in the Ft-M19 locus, VNTR typing, INDEL, SNP, and MALDI-TOF analysis. This is important because it improves our understanding of the spread of tularemia and may help to recognize outbreaks that are not of natural origin.

\section{Results}

\section{Cultivation and identification of isolates}

Cultivation of bacteria from organ specimens was successful in 31 of 52 hares which had a positive PCR result targeting the locus Ft-M19 that was also used to differentiate $F$. tularensis subsp. holarctica from other $F$. tularensis subsp. [11]. F. tularensis subsp. holarctica was identified in all 52 cases.

\section{Biovars}

Seventeen isolates were susceptible to erythromycin corresponding to biovar I, whereas fourteen were resistant (biovar II). The geographic distribution is given in Table 1, Figure 1 and the susceptibility of the isolates in Additional file 1: Table S2.

\section{VNTR typing}

In a pilot study, six loci (Ft-M3, Ft-M6, Ft-M20, Ft-M21, Ft-M22, and Ft-M24) were amplified and sequenced, but only the loci Ft-M3, Ft-M6, and Ft-M24 were discriminatory. The strains tested in the pilot study are indicated in Additional file 1: Table S2(*). The following identical results were obtained for all these strains: Ft-M20: 255 bp; Ft-M21: 403 bp; Ft-M22: 241 bp. The loci Ft-M3 and Ft-M6 (repeat: TTG GTG AAC TTT CTT GCT CTT) were further used to analyse DNA samples extracted from cultivated bacteria. Sequencing of Ft-M3 identified two different repetitive elements, Ft-M3a (ATC CTT ATT), and Ft-M3b (GTC TTT GTT), respectively. The number of these repeats was determined separately. The size obtained for Ft-M24 (repeat: ATA AAT TAT TTA TTT TGA TTA) correlated with the size observed previously for the B.IV (B.18) clade. All VNTR results are given in Additional file 1: Table S2.

\section{INDEL analysis}

Conventional PCR assays with subsequent gel electrophoretic size determination of the amplicon allowed clear discrimination between amplicons with or without the respective deletions which was confirmed by sequencing in some cases (data not shown). The 31 isolates showed four different INDEL patterns (Additional file 1: Table S2). Based on INDELs and SNPs (see below) 14 isolates were assigned to clade B.I (B.20), one to B.II (B.17), and 16 to B.IV (B.18), according to the nomenclature in Karlsson 
Table 1 Original and geographic data of Francisella tularensis subsp. holarctica isolates (BW - Baden-Württemberg, BY - Bavaria, NRW - North Rhine-Westphalia, LS - Lower Saxony, SN - Saxony, TH - Thuringia)

\begin{tabular}{|c|c|c|c|c|c|c|}
\hline Year & Strain number & Site & Federal state & Latitude ['NORTH] & Longitude [ $\left.{ }^{\circ} E A S T\right]$ & Altitude [m] \\
\hline 2006 & 06T0001 & Moorgrund & $\mathrm{TH}$ & 50,838005 & 10,291767 & 279 \\
\hline 2007 & 08T0001 & Dingelstädt & $\mathrm{TH}$ & 51,315205 & 10319329 & 335 \\
\hline 2007 & 08T0008 & Allersberg & BY & 49,251389 & 11,234261 & 388 \\
\hline 2007 & 08T0010 & Sehnde & LS & 52,31262 & 9,967105 & 71 \\
\hline 2007 & 08T0013 & Ehingen & BY & 49,300734 & 10,571476 & 415 \\
\hline 2008 & 08T0014 & Weissach-Flacht & BW & 48,833991 & 8,91309 & 406 \\
\hline 2008 & 08T0015 & Leonberg-Höfingen & BW & 48,816676 & 9,016877 & 379 \\
\hline 2007 & 08Т0070 & Einbeck-Kohnsen & LS & 51,707717 & 10,000538 & 121 \\
\hline 2008 & 08T0071 & Brake & LS & 53,326329 & 8,478167 & 2 \\
\hline 2008 & 08T0072 & Göttingen-Roringen & LS & 51,532638 & 9,92816 & 153 \\
\hline 2008 & 08T0073 & Twülpstedt-Rümmer & LS & 52,224403 & 11,01102 & 127 \\
\hline 2008 & 08T0075 & Würzburg & BY & 49,794256 & 9,927489 & 173 \\
\hline 2009 & 09T0105 & Geseke & NRW & 51,639416 & 8,509738 & 105 \\
\hline 2009 & 09T0108 & Geseke & NRW & 51,639416 & 8,509738 & 105 \\
\hline 2009 & 09T0109 & Geseke & NRW & 47,724358 & 9,406025 & 518 \\
\hline 2009 & 09T0114 & Markdorf & BW & 51,639416 & 8,509738 & 105 \\
\hline 2009 & 09T0116 & Geseke & NRW & 51,444502 & 12,169177 & 115 \\
\hline 2009 & 09T0146 & Wiedemar & SN & 48,864962 & 9,024819 & 337 \\
\hline 2008 & 09T0163 & Hemmingen & BW & 53,770141 & 7,693722 & 1 \\
\hline 2008 & 09T0164 & Spiekeroog & LS & 53,770141 & 7,693722 & 1 \\
\hline 2008 & 09T0165 & Spiekeroog & LS & 53,770141 & 7,693722 & 1 \\
\hline 2008 & 09T0166 & Spiekeroog & LS & 53,770141 & 7,693722 & 1 \\
\hline 2008 & 09T0167 & Spiekeroog & LS & 53,770141 & 7,693722 & 1 \\
\hline 2008 & 09T0169 & Spiekeroog & LS & 53,745892 & 7,480842 & 4 \\
\hline 2008 & 09T0171 & Langeoog & LS & 53,745892 & 7,480842 & 4 \\
\hline 2009 & 09T0179 & Langeoog & LS & 53,745892 & 7,480842 & 4 \\
\hline 2010 & 10T0014 & Hemmingen & BW & 52,314054 & 9,722783 & 56 \\
\hline 2010 & 10T0115 & Waltrop & NRW & 51,624087 & 7,39465 & 69 \\
\hline 2010 & 10T0125 & Geseke & NRW & 51,639223 & 8,469223 & 103 \\
\hline 2010 & 10T0128 & Empfingen & BW & 48,391957 & 8,708282 & 491 \\
\hline 2010 & 10т0131 & Oppenweiler & BW & 48,985678 & 9,460219 & 270 \\
\hline
\end{tabular}

et al. 2013 [16], where the B.I clade was re-defined to include both B1 and B3 in Svensson et al. [15].

\section{SNP typing}

The results of SNP typing are given in Additional file 1: Table S2. All strains used in a pilot study showed ancestral states of the following SNPs: B.16: G; B.21:G; B.22:G; B.24:T. These strains are indicated ${ }^{*}$ ) in Additional file 1: Table S2. Therefore, only the SNPs B.17, B.18, B.19, and B.20 were further investigated for all isolates.

\section{MALDI-TOF MS analysis}

All isolates $(n=31)$ yielded high quality spectra. MALDITOF was found to be useful for rapid identification of isolates to subspecies level within one hour. However, the obtained clusters (Figure 2) did not conform to the genetic clusters (Additional file 1: Table S2).

\section{Geographical clustering}

Cases of tularemia in hares were identified in eight of sixteen federal states of Germany reaching from islands in the North Sea to regions at Lake Constance in the southern 


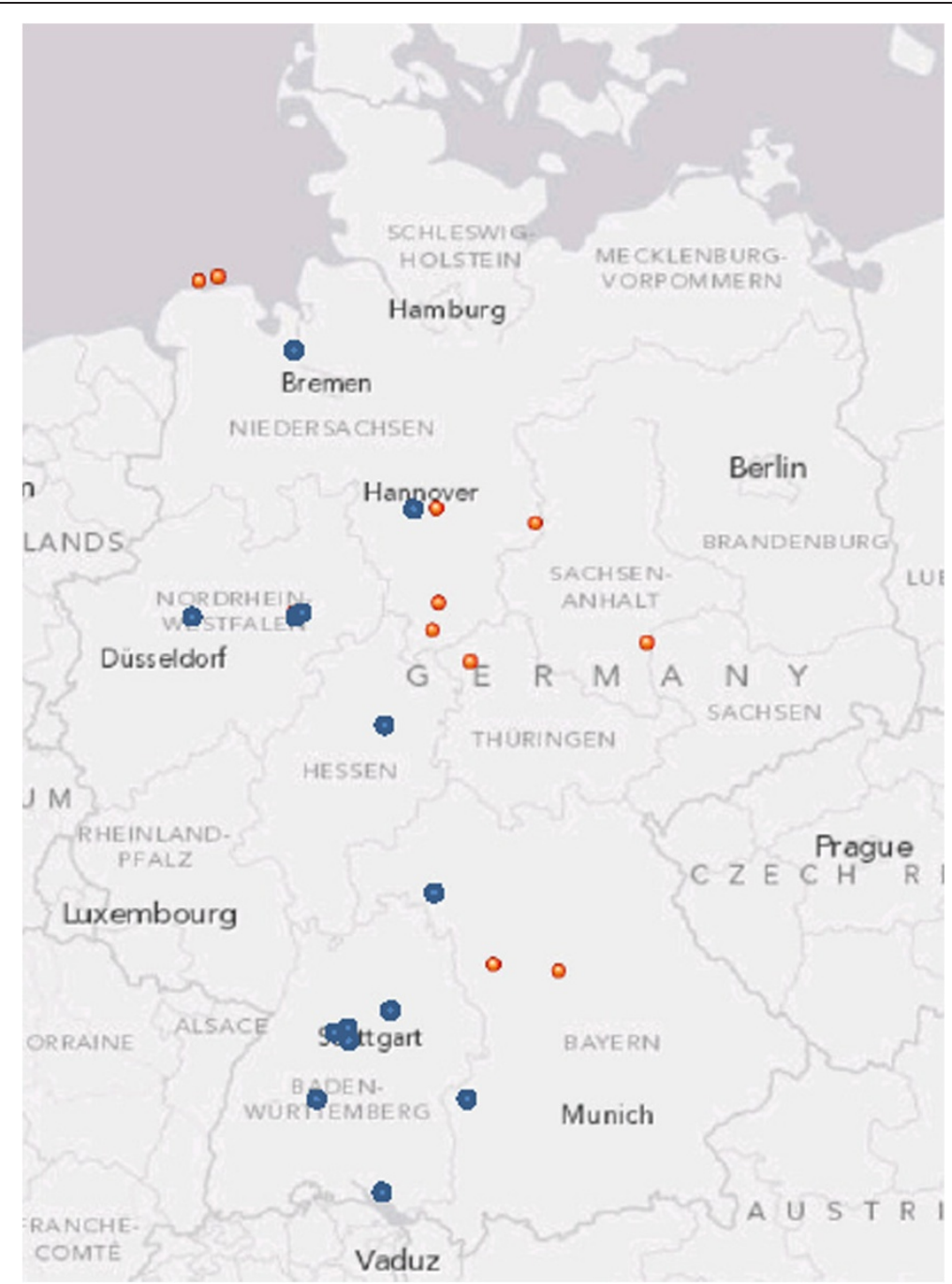

Figure 1 Germany: areas where Francisella tularensis subsp. holarctica isolates were found in hares. Erythromycin sensitive strains occur in regions marked with blue dots, erythromycin resistant strains occur in regions marked with red dots.

part of Germany. All cases were found below $500 \mathrm{~m}$ above sea level. Isolates belonging to biovar I could be found in the western part of Germany whereas biovar II occurred in the eastern region (Table 1 and Additional file 1: Table S2, Figure 1). Molecular typing resulted in further discrimination of clusters within the biovars. Isolates resistant to erythromycin and genetically assigned to clade B.I were found only in Lower Saxony, Thuringia, Bavaria and Saxony. Strains that were sensitive to erythromycin could be assigned to clade B.II (Ftind38) and B.IV (B.18) as given in Additional file 1: Table S2.

\section{Stability testing}

The investigated markers for two Francisella isolates (06T0001 from hare and 10T0191 from fox) were stable even after 20 passages in cell culture and had identical results for the markers Ft-M3 (297 bp), Ft-M6 (311 bp),
Ftind33 (deletion), Ftind38 (insertion), and Ftind49 (insertion).

\section{Discussion}

In Thuringia the first case of tularemia in a hare was reported in 2006 [17]. In Lower Saxony 2,162 European brown hares and European rabbits (Oryctolagus cuniculus) were screened for tularemia between 2006 and 2009 using cultivation and PCR assays. Francisella specific PCR assays were positive in 23 hares and 1 rabbit which were further confirmed by cultivation of $F$. tularensis subsp. holarctica in 12 hares [18]. In the present study, cases of tularemia in hares in Germany from 2005 to 2010 were investigated. During this period a total of 52 hares were found positive in PCR assays for F. tularensis subsp. holarctica DNA and from 31 of these cases Francisella strains could be isolated. MALDI-TOF analysis was also 


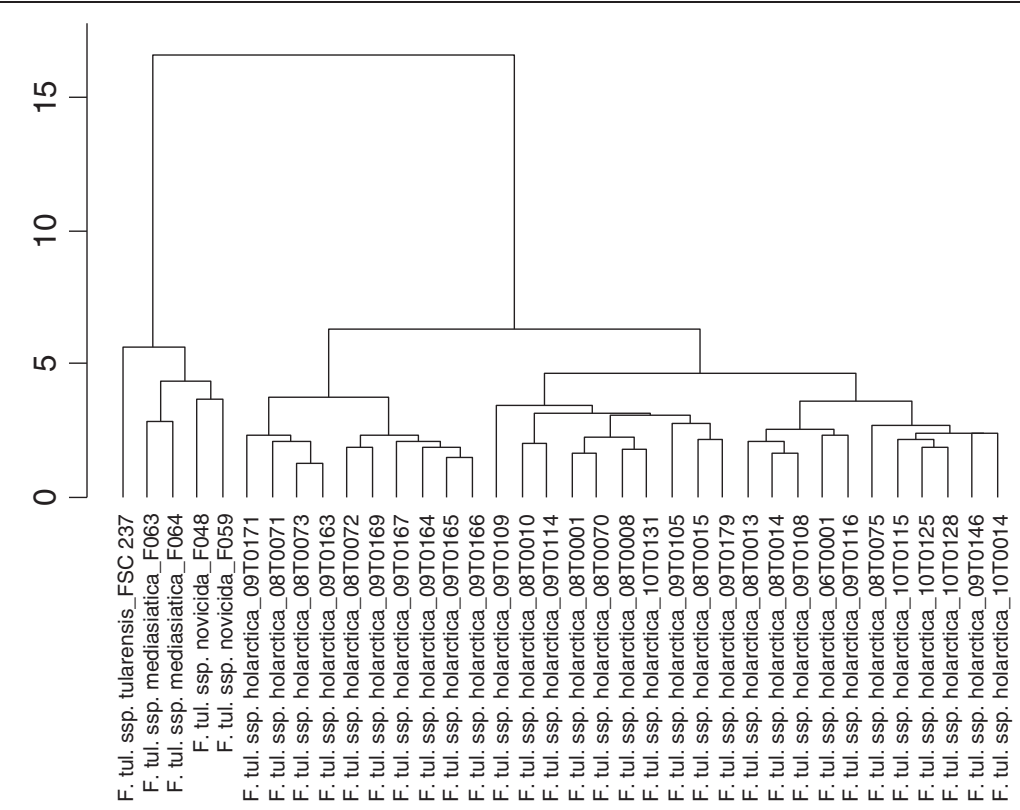

Figure 2 Dendrogram constructed from MALDI-TOF mass spectrometry spectra of 31 Francisella tularensis ssp. holarctica strains and representatives of ssp. tularensis, mediasiatica, and novicida.

used to rapidly identify Francisella to the subspecies level as was previously shown by Seibold et al. [19].

Several positive specimens were found on the North Sea islands Langeoog and Spiekeroog (LS), around Soest (NR), Darmstadt $(\mathrm{H})$, and Böblingen (BW). These natural foci and also sporadic cases in other regions of Germany were found below $500 \mathrm{~m}$ above sea level. In the Czech Republic typical natural foci of tularemia occurred in alluvial forests and field biotopes below $200 \mathrm{~m}$ sea level with mean annual air temperature between $8.1-10.0^{\circ} \mathrm{C}$ and mean annual precipitation of 450-700 mm [20]. In Germany, an outbreak of tularemia in a colony of semi-free living marmosets was located in a region with geographic and ecological conditions similar to the hare habitats in the Czech Republic: field biotopes $175 \mathrm{~m}$ above sea level $(<200 \mathrm{~m})$ with $9.2^{\circ} \mathrm{C}$ mean annual air temperature and $642 \mathrm{~mm}$ mean annual precipitation [8]. In Germany, tularemia of hares occurs in regions with rather humid soil like in alluvial forests and alongside rivers, but this obviously corresponds with the natural habitat of hares.

Specimens were screened using a PCR assay targeting Ft-M19 described by Johansson et al. [11] which allows the simultaneous identification of the species F. tularensis and the differentiation of the subspecies holarctica from other (sub-) species. All samples could be attributed to F. tularensis subsp. holarctica.

We found a clear segregation of clade B.I and clade B.IV in Germany, B.I strains dominate in eastern Germany and B.IV within western Germany (Figure 1). Clade B.I is known to dominate in Europe between Scandinavia and the Black Sea [15,16,21-23]. The other dominating
European clade is B.IV (B.18) which can be found over a large area of western and central Europe, and, based upon this study, western Germany [21,23-26]. We found only one strain of the B.II clade isolated in Bavaria. Strains of the B.II clade are most frequently isolated in the USA, but are found sporadically in Europe as well [16,21].

The phylogeographical pattern of clade B.I and B.IV, coincide with the geographical distribution of biovar II and biovar I strains, respectively. Previously, biovar I strains (erythromycin sensitive) have been reported from Western Europe (France, Germany, Spain and Switzerland), NorthAmerica, Eastern Siberia and the Far East while biovar II is present in the European part of Russia as well as Northern, Central and Eastern Europe (Austria, Germany, Sweden and Turkey) [27-31]. A mixture of both biotypes has been reported in Sweden, Norway, Bulgaria, Russia and Kazakhstan [27,28,32]. Isolation of both biovars from rodents in a single settlement in Moscow as well as from water samples collected in the Novgorod region [27] indicate coexistence of the biovars in the same epidemiological foci. Taken together, a geographical separation of F. tularensis strains seems to exist in Germany. The phenotypically defined biovar I (erythromycin sensitive) and phylogenetically defined clade B.IV strains are confined in western Germany, whereas biovar II (erythromycin resistance) and clade B.I strains cluster in eastern Germany. This is interesting and may reflect a competition between the two subpopulations or unknown underlying ecological or epidemiological differences.

A deletion in the genome of $F$. tularensis subsp. holarctica in $\mathrm{RD}_{23}$ is typical for strains of $F$. tularensis 
subsp. holarctica in France, the Iberian Peninsula and also Switzerland, where biovar I predominates [24,25,27]. However, in one erythromycin susceptible isolate from Bavaria (08T0013), classified in this study as belonging to the B.II clade, $\mathrm{RD}_{23}$ was not deleted, thus showing that deletion of $\mathrm{RD}_{23}$ is not correlated with sensitivity to erythromycin. The molecular mechanisms of resistance to erythromycin have not been functionally established, but mutations identified in domain $\mathrm{V}$ of the 23S rRNA of biovar II strains, could provide a likely explanation [33].

Although 25 VNTR markers have been described for the typing of Francisella, it is pragmatic to investigate only loci of interest depending on the prevalent subspecies of F. tularensis, the efficiency of PCR assays for single loci, and existing data $[1,13,34]$. Sequence analysis of the locus Ft-M3 resulted in two different repeats denominated here as Ft-M3a corresponding with SSTR9E and Ft-M3b corresponding with SSTR9A as described previously by Johansson et al. [35]. Johansson et al. and Byström et al. also found that locus Ft-M3 is the most variable marker $[1,13]$. In the Francisella genome variations of DNA sequences in spite of identical repeat length have been described for short-sequence tandem repeats [35,36]. Locus Ft-M6 showed less variability with only three PCR fragment sizes being observed among the strains. We obtained the same amplicon sizes that were described in previous studies for locus Ft-M3 (Additional file 1: Table S2) $[14,37]$ and for locus Ft-M6 (Additional file 1: Table S2) $[14,37]$. Svensson et al. developed a sophisticated real-time PCR array for hierarchical identification of Francisella isolates [15]. Only three (Ftind33, Ftind38, Ftind49) out of five INDEL loci were discriminatory among our set of F. tularensis subsp. holarctica isolates. Ftind48 is a marker for B.I to B.IV clades (non-japonica/non-california) and is not expected to vary for these isolates, and Ftind50 is targeting a specific deletion that so far only has been found in LVS. It was possible to simplify these assays to conventional PCR assays that allowed a simple read out based on gel electrophoresis. We identified clusters of strains that had the same INDELs and SNPs as strains described by Svensson et al. [15]. In our study the analysis of VNTR and INDELs of two F. tularensis subsp. holarctica strains (06T0001, 10T0191) that were passaged twenty times in Ma-104 cells showed that these genomic elements were stable. Johansson et al. demonstrated for two VNTR loci (SSTR9 and SSTR16) that they were actually stable over 55 passages [35]. The VNTR pattern for strains belonging to clade B.I was more variable compared with the pattern obtained for clade B. IV (Additional file 1: Table S2), as was observed previously [21,23-25]. This might indicate that clade B.IV is more recently introduced in Germany than clade B.I.

We have applied several typing tools in a polyphasic approach in order to determine their value for identifying groups of Francisella strains in Germany. We found strains belonging to biovars I and II of $F$. tularensis subsp. holarctica. Although SNP loci are the most informative markers for typing of Francisella this method may have to be adapted to local strains $[37,38]$.

\section{Conclusions}

F. tularensis seems to be a re-emerging pathogen in Germany that infects hares in many regions and causes a potential risk for exposed humans such as hunters and others who process hares. The pathogen can easily be identified using PCR assays directly on DNA extracted from organ specimens or cultivated strains. Isolates can also be identified rapidly using MALDI-TOF MS in routine laboratories where specific PCR assays for F. tularensis are not established. To identify differences and genetic relatedness of Francisella strains, analysis of VNTR loci (Ft-M3, Ft-M6 and Ft-M24), INDELs (Ftind33, Ftind38, Ftind49, RD23) and SNPs (B.17, B.18, B.19, and B.20) was shown to be useful in this set of strains. When time and costs are limiting parameters isolates can be analysed using simplified PCR assays with a focus on genetic loci that are most likely discriminatory among strains found in a specific area. For the future whole genome sequencing using next generation sequencing is desirable and should provide more genetic information of Francisella strains. Based on these data a more detailed view on the epidemiology of tularemia will become possible [39].

\section{Methods}

\section{Samples}

Organ specimens (e.g. spleen, liver, lung, and/or kidney) of European brown hares that were suspicious of tularemia were collected by local veterinary authorities in Germany since 2005 and sent for confirmatory testing to the National Reference Laboratory for Tularemia of the Friedrich-Loeffler-Institut in Jena. Francisella strains were cultivated on cysteine heart agar (Becton Dickinson $\mathrm{GmbH}$, Heidelberg, Germany) supplemented with 10\% chocolatized sheep blood and antibiotics in order to suppress the growth of contaminants. One litre of culture medium contained $100 \mathrm{mg}$ ampicillin (Sigma-Aldrich Chemie, Taufkirchen, Germany) and $600000 \mathrm{U}$ polymyxin B (Sigma-Aldrich Chemie). Plates were incubated at $37^{\circ} \mathrm{C}$ with $5 \% \mathrm{CO}_{2}$ for up to 10 days. Typical colonies are grey-green, mostly confluent, glossy, and opaque. Gram staining was performed routinely and showed Gram negative coccoid bacteria.

The reference strains F. tularensis subsp. tularensis (FSC 237), mediasiatica (FSC 147), and F. novicida (ATCC 15482) were obtained from the Bundeswehr Institute of Microbiology, Munich, Germany, and $F$. philomiragia (DSMZ 7535) was obtained from the 
German Collection of Microorganisms and Cell Cultures, Braunschweig, Germany, respectively.

\section{Erythromycin susceptibility}

All F. tularensis subsp. holarctica isolates were tested for their erythromycin susceptibility using Erythromycin discs [30 $\mu \mathrm{g}$ ] and M.I.C.Evaluator ${ }^{\mathrm{TM}}$ (Oxoid, Wesel, Germany) in order to discriminate the susceptible biovar I from the resistant biovar II as described previously [40].

\section{DNA extraction}

$50 \mathrm{mg}$ of organ material or $200 \mu \mathrm{l}$ of cell culture supernatant were lysed and the DNA was extracted using the High Pure PCR Template Preparation Kit (Roche Diagnostics, Mannheim, Germany) according to the manufacturer`s instructions. If cultivation was successful some colonies were resuspended in $200 \mu \mathrm{l}$ phosphate-buffered saline, boiled at $90^{\circ} \mathrm{C}$ for 10 minutes and DNA was prepared as described above. Finally, DNA was eluted in 200 $\mu \mathrm{l}$ elution buffer. $5 \mu \mathrm{l}$ were applied in each PCR assay.

\section{Diagnostic PCR assay}

F. tularensis subsp. holarctica was identified using a PCR assay with primer pair $\mathrm{C} 1 / \mathrm{C} 4$ targeting the locus Ft-M19 that distinguishes the two major subspecies $F$. tularensis subsp. holarctica and $F$. tularensis subsp. tularensis which was carried out as described by Johansson et al. [11].

\section{VNTR typing}

In pilot experiments 6 VNTR loci (Ft-M3, Ft-M6, Ft-M20, Ft-M21, Ft-M22, and Ft-M24) were investigated as described by Byström et al. [13]. The loci found discriminatory were then subsequently analysed in all 31 isolates. The amplification of the VNTR loci was carried out under the same cycling conditions as the diagnostic PCR assay except for the annealing temperature of $56^{\circ} \mathrm{C}$. The fragments were cut out of the agarose gel and DNA was purified using the innuPrep Gel Extraction Kit (Analytik Jena AG, Jena, Germany) according to the manufacturer's instructions. Subsequently, DNA amplificates were sequenced as described below.

\section{INDEL analysis}

Five INDELs (Ftind33, Ftind38, Ftind48, Ftind49, and Ftind50) that are discriminatory among $F$. tularensis subsp. holarctica were selected from the loci described by Svensson et al. [15]. The real-time PCR assays with melting curve analyses were simplified by using conventional PCR assays. The primers "CP" and "OUT" for the respective loci were used as described by Svensson et al. The reaction mixture consisted of $5 \mu \mathrm{l} 10 \mathrm{x}$ PCR buffer with $1.5 \mathrm{mM} \mathrm{MgCl}_{2}$ (Genaxxon, Stafflangen, Germany), $2 \mu \mathrm{l}$ of dNTP mix (each $2 \mathrm{mM}$, Carl Roth GmbH,
Karlsruhe, Germany), $1 \mu \mathrm{l}$ of each primer, $0.2 \mu \mathrm{l}$ of Taq DNA polymerase ( $5 \mathrm{U} / \mu \mathrm{l}$, Genaxxon), $5 \mu \mathrm{l}$ of DNA extract and deionised water to a final volume of $50 \mu \mathrm{l}$. After denaturation at $95^{\circ} \mathrm{C}$ for $5 \mathrm{~min}, 35$ cycles of amplification were performed with denaturation at $95^{\circ} \mathrm{C}$ for $30 \mathrm{~s}$, primer annealing at $60^{\circ} \mathrm{C}$ for $60 \mathrm{~s}$, and primer extension at $72^{\circ} \mathrm{C}$ for $30 \mathrm{~s}$. After a final extension step at $72^{\circ} \mathrm{C}$ for $30 \mathrm{~s}$ amplicons were separated using $2.5 \%$ agarose gel electrophoresis and visualized using ethidium bromide staining under UV light.

\section{SNP typing}

Four of ten SNPs (B.17, B.18, B.19, and B.20) that have been found to be useful for the typing of $F$. tularensis subsp. holarctica strains were selected from the loci described by Svensson et al. [15]. The primers " $C$ " and " $D$ " for the respective loci described by Svensson et al. were used, but the primers " $\mathrm{D}$ " were shortened by removing the SNP specific last nucleotide and the non-binding GC-rich tails that were originally added to the allele-specific primer (i.e. gcgggcagggcggc). SNPs were detected by sequence analysis of the PCR products. The nomenclature used for the designation of clades is according to Karlsson et al. 2013 [16].

\section{DNA sequencing}

Purified DNA fragments were subjected to cycle sequencing with BigDye ${ }^{\mathrm{TM}}$ Terminator Cycle Sequencing Ready Reaction Kit (Applied Biosystems, Darmstadt, Germany). Amplification primers were also used as sequencing primers. Nucleotide sequences were determined on an ABI Prism 310 Genetic Analyzer (Applied Biosystems).

\section{Analysis of sequence data}

VNTR sequence data were aligned using BioEdit (Biological sequence alignment editor, Ibis Therapeutics, Carlsbad, CA, USA).

\section{Stability testing}

The stability of the markers Ft-M3, Ft-M6, Ftind33, Ftind38, and Ftind49 was assessed for two F. tularensis subsp. holarctica strains that were isolated from a hare (06T0001) and a red fox (Vulpes vulpes) (10T0191), respectively. The isolates were passaged twenty times on MA-104 cells in $12.5 \mathrm{ml}$ cell culture flasks (Becton Dickinson GmbH, Heidelberg, Germany). Confluent monolayers of MA-104 cells were washed with phosphate- buffered saline, $\mathrm{pH}$ 7.4. The bacterial suspensions or cell culture samples were inoculated on the cells at $37^{\circ} \mathrm{C}$ for $1 \mathrm{~h}$. The inoculum was replaced with Dulbecco's Modified Eagle's Medium (DMEM) and incubated at $37^{\circ} \mathrm{C}$ in a humidified air atmosphere with $5 \% \mathrm{CO}_{2}$. After incubation for 3 to 5 days when the cells detached from the surface, the bacteria were harvested by two freeze-thaw cycles. The bacteria/cell suspensions were used for preparation of DNA. 


\section{MALDI-TOF typing}

Samples were taken from single colonies, ethanolprecipitated and extracted with $70 \%$ formic acid as described by Sauer et al. [41]. The extract was diluted with one volume acetonitrile and $1.5 \mu \mathrm{L}$ of the mixture was spotted to a steel MALDI target. The dried extract was overlaid with $1.5 \mu \mathrm{L}$ of a saturated solution of $\alpha$-cyano-4-hydroxycinnamic acid in 50\% acetonitrile/ $2.5 \%$ trifluoroacetic acid as matrix and was again allowed to dry. A custom-made database of reference spectra, or main spectra (MSP), was constructed using the BioTyper software (version 1.1, Bruker Daltonics, Bremen, Germany) following the guidelines of the manufacturer. Each sample was spotted six-fold and four single spectra with 500 laser pulses each were acquired from each spot with an Ultraflex I instrument (Bruker Daltonics) in the linear positive mode in the range of 2,000 to $15,000 \mathrm{Da}$. Acceleration voltage was $25 \mathrm{kV}$ and the instrument was calibrated in the range of 4,364 to $10,299 \mathrm{Da}$ with reference masses of an extract of an Escherichia coli DH5.alpha; strain prepared according to Sauer et al. [41]. MSP were generated within the mass range of 2,500 to 15,000 $\mathrm{Da}$ with the following default parameters: compression of the spectrum data by a factor of 10, baseline smoothing by the Savitsky-Golay algorithm ( $25 \mathrm{Da}$ frame size), baseline correction by 2 runs of the multi-polygon algorithm, and peak search by spectra differentiation. The number of peaks was limited to 100 per MSP and all peaks were normalized to the most intense peak with an intensity of 1.0. The minimum frequency of occurrence within the 24 single spectra was set to $50 \%$ for every mass. Peak lists of MSP were exported for further evaluation.

\section{Additional file}

Additional file 1: Table S2. Results of VNTR, SNP, INDEL analysis and erythromycin sensitivity testing of Francisella tularensis subsp. holarctica isolates. The number of repeats is given for Ft-M3a, Ft-M3b, and Ft-M6. The number of base-pairs is given for Ft-M24. Derived state of SNPs and INDELs is in boldface. Nomenclature is according to Karlsson et al. (2013) [16], where the B.I clade was re-defined to include both B1 and B3 [15] (DEL, deletion; IN, insertion; bp, basepairs; BW - Baden-Württemberg, BY Bavaria, NRW - North Rhine-Westphalia, LS - Lower Saxony, SN - Saxony, TH - Thuringia; n.d., not done).

\section{Competing interests}

The authors declare that they have no competing interests.

\section{Authors' contributions}

WM participated in the design of the study, evaluated VNTR data and drafted the manuscript. HH performed PCR assays and DNA sequencing and critically revised the manuscript. PO performed cultivation on nutrient agar and cell culture, erythromycin susceptibility testing, and critically revised the manuscript. AK performed MALDI-TOF MS experiments, data analysis and drafted the respective sections in the manuscript. BB performed MALDI-TOF MS experiments and data analysis. HB isolated and cultivated strains and critically revised the manuscript. SB performed post mortem examination and bacterial culture and revised the manuscript. UE performed post mortem examination and bacterial culture and revised the manuscript. SH provided sample specimens and strains and critically revised the manuscript. RK provided sample specimens and strains and critically revised the manuscript. AN performed post mortem examination and bacterial culture and revised the manuscript. MP contributed tissues of hares with tularemia from the region of Soest (NRW). MR did PCR assays to identify Francisella tularensis in samples and bacterial cultures and revised the manuscript. GS participated in the data analysis and critically revised the manuscript. BAS isolated and cultivated a Francisella tularensis strain from European brown hare in Saxony and critically revised the manuscript. RS isolated and cultivated a Francisella tularensis strain from European brown hare in Bavaria and critically revised the manuscript. KM participated in the data analysis of typing data and critically revised the manuscript. EK typed strains and critically revised the manuscript. MF participated in the data analysis and critically revised the manuscript. HT participated in the design of the study, coordinated the experiments, analysed the data, and finalized the manuscript. All authors read and approved the final manuscript.

\section{Acknowledgements}

We are grateful to Kerstin Cerncic, Renate Danner, Byrgit Hofmann, and Karola Zmuda for their excellent technical assistance.

\section{Author details}

${ }^{1}$ Institute of Bacterial Infections and Zoonoses, Friedrich-Loeffler-Institut (Federal Research Institute for Animal Health), Naumburger Str. 96A, Jena D-07743, Germany. ${ }^{2}$ Institute of Molecular Biology, Friedrich-Loeffler-Institut (Federal Research Institute for Animal Health), Südufer 10, Greifswald-Insel Riems D-17493, Germany. ${ }^{3}$ Thüringer Landesamt für Lebensmittelsicherheit und Verbraucherschutz, Tennstedter Str. 9, Bad Langensalza D-99947, Germany. ${ }^{4}$ Lower Saxony State Office for Consumer Protection and Food Safety, Eintrachtweg 17, Hannover D-30173, Germany. ${ }^{5}$ Landesbetrieb Hessisches Landeslabor, Schubertstr. 60, Gießen D-35393, Germany. ${ }^{6}$ Bayerisches Landesamt für Gesundheit und Lebensmittelsicherheit, Veterinärstr. 2, Oberschleißheim D-85764, Germany. ${ }^{7}$ Staatliches Veterinäruntersuchungsamt Arnsberg, Zur Taubeneiche 10-12, Arnsberg D-59821, Germany. ${ }^{8}$ Official Laboratory for Public and Veterinary Health Saxony, Leipzig, Bahnhofstr. 58-60, Leipzig D-04158, Germany. ${ }^{9}$ Chemisches und Veterinäruntersuchungsamt Stuttgart, Schaflandstr. 3/3, Fellbach D-70763, Germany. ${ }^{10} \mathrm{CBRN}$ Defence and Security, Swedish Defence Research Agency (FOI), Umeå SE-90182, Sweden.

Received: 16 February 2012 Accepted: 15 March 2013 Published: 21 March 2013

\section{References}

1. Johansson A, Farlow J, Larsson P, Dukerich M, Chambers E, Byström M, Fox J, Chu M, Forsman M, Sjöstedt A, Keim P: Worldwide genetic relationships among Francisella tularensis isolates determined by multiple-locus variable-number tandem repeat analysis. J Bacterio/ 2004, 186:5808-5818.

2. Keim P, Johansson A, Wagner DM: Molecular epidemiology, evolution, and ecology of Francisella. Ann N Y Acad Sci 2007, 1105:30-66.

3. Petersen JM, Schriefer ME: Tularemia: emergence/re-emergence. Vet Res 2005, 36:455-467.

4. Ellis J, Oyston PC, Green M, Titball RW: Tularemia. Clin Microbiol Rev 2002, 15:631-646.

5. Knothe H: Epidemiology of tularemia. Beitr Hyg Epidemiol 1955, 7:1-122.

6. Grunow R, Priebe H: Tularämie - zum Vorkommen in Deutschland. Epidemiol Bull 2007, 7:51-56.

7. Splettstoesser WD, Mätz-Rensing K, Seibold E, Tomaso H, Al Dahouk S, Grunow R, Essbauer S, Buckendahl A, Finke EJ, Neubauer H: Re-emergence of Francisella tularensis in Germany: fatal tularaemia in a colony of semi-freeliving marmosets (Callithrix jacchus). Epidemiol Infect 2007, 135:1256-1265.

8. Hofstetter I, Eckert J, Splettstoesser W, Hauri AM: Tularaemia outbreak in hare hunters in the Darmstadt-Dieburg district, Germany. Euro Surveill 2006, 11, E060119.3.

9. Splettstoesser WD, Tomaso H, Al Dahouk S, Neubauer $H$, Schuff-Werner P: Diagnostic procedures in tularaemia with special focus on molecular and immunological techniques. J Vet Med B Infect Dis Vet Public Health 2005, 52:249-261 
10. Johansson A, Berglund L, Eriksson U, Göransson I, Wollin R, Forsman M Tärnvik A, Sjöstedt A: Comparative analysis of PCR versus culture for diagnosis of ulceroglandular tularemia. J Clin Microbiol 2000, 38:22-26.

11. Johansson A, Ibrahim A, Göransson I, Eriksson U, Gurycova D, Clarridge JE 3rd, Sjöstedt A: Evaluation of PCR-based methods for discrimination of Francisella species and subspecies and development of a specific PCR that distinguishes the two major subspecies of Francisella tularensis. J Clin Microbiol 2000, 38:4180-4185.

12. Farlow J, Smith KL, Wong J, Abrams M, Lytle M, Keim P: Francisella tularensis strain typing using multiple-locus, variable-number tandem repeat analysis. J Clin Microbiol 2001, 39:3186-3192.

13. Byström M, Böcher S, Magnusson A, Prag J, Johansson A: Tularemia in Denmark: identification of a Francisella tularensis subsp. holarctica strain by real-time PCR and high-resolution typing by multiple-locus variablenumber tandem repeat analysis. J Clin Microbiol 2005, 43:5355-5358.

14. Vogler AJ, Birdsell D, Price LB, Bowers JR, Beckstrom-Sternberg SM, Auerbach RK, Beckstrom-Sternberg JS, Johansson A, Clare A, Buchhagen JL, Petersen JM, Pearson T, Vaissaire J, Dempsey MP, Foxall P, Engelthaler DM, Wagner DM, Keim P: Phylogeography of Francisella tularensis: global expansion of a highly fit clone. J Bacteriol 2009, 191:2474-2484.

15. Svensson K, Granberg M, Karlsson L, Neubauerova V, Forsman M, Johansson A: A real-time PCR array for hierarchical identification of Francisella isolates. PLoS One 2009, 4:e8360.

16. Karlsson $E$, Svensson $K$, Lindgren $P$, Byström M, Sjödin A, Forsman $M$, Johansson A: The phylogeographic pattern of Francisella tularensis in Sweden indicates a Scandinavian origin of Eurosiberian tularaemia. Environ Microbiol 2012. doi:10.1111/1462-2920.12052. n/a-n/a.

17. Müller W, Bocklisch H, Schüler G, Hotzel H, Neubauer H, Otto P: Detection of Francisella tularensis subsp. holarctica in a European brown hare (Lepus europaeus) in Thuringia, Germany. Vet Microbiol 2007, 123:225-229.

18. Runge M, Von Keyserlingk M, Braune S, Voigt S, Grauer S, Pohlmeyer K, Wedekind M, Splettstoesser WD, Seibold E, Otto P, Müller W: Prevalence of Francisella tularensis in brown hare (Lepus europaeus) populations in Lower Saxony, Germany. Eur J Wildlife Res 2011, 57:1085-1089.

19. Seibold E, Maier T, Kostrzewa M, Zeman E, Splettstoesser W: Identification of Francisella tularensis by whole-cell matrix-assisted laser desorption ionization-time of flight mass spectrometry: fast, reliable, robust, and cost-effective differentiation on species and subspecies levels. J Clin Microbiol 2010, 48:1061-1069

20. Pikula J, Treml F, Beklova M, Holesovska Z, Pikulova J: Ecological conditions of natural foci of tularaemia in the Czech Republic. Eur J Epidemiol 2003, 18:1091-1095

21. Vogler AJ, Birdsell DN, Lee J, Vaissaire J, Doujet CL, Lapalus M, Wagner DM, Keim P: Phylogeography of Francisella tularensis ssp. holarctica in France. Lett Appl Microbiol 2011, 52:177-180.

22. Chanturia G, Birdsell DN, Kekelidze M, Zhgenti E, Babuadze G, Tsertsvadze N, Tsanava S, Imnadze P, Beckstrom-Sternberg SM, Beckstrom-Sternberg JS, Champion MD, Sinari S, Gyuranecz M, Farlow J, Pettus AH, Kaufman EL, Busch JD, Pearson T, Foster JT, Vogler AJ, Wagner DM, Keim P: Phylogeography of Francisella tularensis subspecies holarctica from the country of Georgia. BMC Microbiol 2011, 11:139.

23. Gyuranecz M, Birdsell DN, Splettstoesser W, Seibold E, Beckstrom-Sternberg SM, Makrai L, Fodor L, Fabbi M, Vicari N, Johansson A, Busch JD, Vogler AJ, Keim P, Wagner DM: Phylogeography of Francisella tularensis subsp. holarctica, Europe. Emerg Infect Dis 2012, 18:290-293.

24. Dempsey MP, Dobson M, Zhang C, Zhang M, Lion C, Gutiérrez-Martín CB, Iwen PC, Fey PD, Olson ME, Niemeyer D, Francesconi S, Crawford R, Stanley M, Rhodes J, Wagner DM, Vogler AJ, Birdsell D, Keim P, Johansson A, Hinrichs SH, Benson AK: Genomic deletion marking an emerging subclone of Francisella tularensis subsp. holarctica in France and the Iberian Peninsula. Appl Environ Microbiol 2007, 73:7465-7470.

25. Pilo P, Johansson A, Frey J: Identification of Francisella tularensis cluster in central and western Europe. Emerg Infect Dis 2009, 15:2049-2051.

26. Gehringer H, Schacht E, Maylaender N, Zeman E, Kaysser P, Oehme R, Pluta S: Presence of an emerging subclone of Francisella tularensis holarctica in Ixodes ricinus ticks from south-western Germany. Ticks Tick-borne Dis 2012:1-8. doi:10.1016/j.ttbdis.2012.09.001.

27. Kudelina RI, Olsufiev NG: Sensitivity to macrolide antibiotics and lincomycin in Francisella tularensis holarctica. J Hyg Epidemiol Microbiol Immunol 1980, 24:84-91.
28. Petersen J, Molins C: Subpopulations of Francisella tularensis ssp. tularensis and holarctica: identification and associated epidemiology. Future Microbiol 2010, 5:649-661.

29. Georgi E, Schacht E, Scholz HC, Splettstoesser WD: Standardized broth microdilution antimicrobial susceptibility testing of Francisella tularensis subsp. holarctica strains from Europe and rare Francisella species. J Antimicrob Chemother 2012, 67:2429-33.

30. Kreizinger Z, Makrai L, Helyes G, Magyar T, Erdélyi K, Gyuranecz M: Antimicrobial susceptibility of Francisella tularensis subsp. holarctica strains from Hungary, Central Europe. J Antimicrob Chemother 2012. doi:10.1093/jac/dks399.

31. Yesilyurt M, Kiliç S, Celebi B, Celik M, Gül S, Erdogan F, Ozel G: Antimicrobial susceptibilities of Francisella tularensis subsp. holarctica strains isolated from humans in the Central Anatolia region of Turkey. J Antimicrob Chemother 2011, 66:2588-92.

32. Kunitsa TN, Meka-Mechenko UV, Izbanova UA, Abdirasilova AA, Belonozhkina LB: Properties of the tularemia microbe strains isolated from natural tularemia foci in Kazakhstan. CO, USA: Presented at 7th International Conference on Tularemia, Breckenridge; 2012:70. S4-32.

33. Biswas $S$, Raoult $D$, Rolain J: A bioinformatic approach to understanding antibiotic resistance in intracellular bacteria through whole genome analysis. Int J Antimicrob Agents 2008, 32:207-220.

34. Goethert HK, Telford SR 3rd: Nonrandom distribution of vector ticks (Dermacentor variabilis) infected by Francisella tularensis. PLoS Pathog 2009, 5:e1000319.

35. Johansson A, Göransson I, Larsson P, Sjöstedt A: Extensive allelic variation among Francisella tularensis strains in a short-sequence tandem repeat region. J Clin Microbiol 2001, 39:3140-3146.

36. Vodop'ianov AS, Vodop'ianov SO, Pavlovich NV, Mishan'kin BN: [Multilocus VNTR-typing of Francisella tularensis strains]. Zh Mikrobiol Epidemiol Immunobiol 2004, 2:21-25.

37. Svensson K, Bäck E, Eliasson H, Berglund L, Granberg M, Karlsson L, Larsson $P$, Forsman M, Johansson A: Landscape epidemiology of tularemia outbreaks in Sweden. Emerg Infect Dis 2009, 15:1937-1947.

38. Pandya GA, Holmes MH, Petersen JM, Pradhan S, Karamycheva SA, Wolcott MJ, Molins C, Jones M, Schriefer ME, Fleischmann RD, Peterson SN: Whole genome single nucleotide polymorphism based phylogeny of Francisella tularensis and its application to the development of a strain typing assay. BMC Microbiol 2009, 9:213.

39. La Scola B, Elkarkouri K, Li W, Wahab T, Fournous G, Rolain JM, Biswas S, Drancourt M, Robert C, Audic S, Löfdahl S, Raoult D: Rapid comparative genomic analysis for clinical microbiology: the Francisella tularensis paradigm. Genome Res 2008, 18:742-750.

40. Tomaso H, Al Dahouk S, Hofer E, Splettstoesser WD, Treu TM, Dierich MP, Neubauer H: Antimicrobial susceptibilities of Austrian Francisella tularensis holarctica biovar II strains. Int J Antimicrob Agents 2005, 26:279-284.

41. Sauer S, Freiwald A, Maier T, Kube M, Reinhardt R, Kostrzewa M, Geider K: Classification and identification of bacteria by mass spectrometry and computational analysis. PLoS One 2008, 3:e2843.181.

doi:10.1186/1471-2180-13-61

Cite this article as: Müller et al:: German Francisella tularensis isolates from European brown hares (Lepus europaeus) reveal genetic and phenotypic diversity. BMC Microbiology 2013 13:61.

\section{Submit your next manuscript to BioMed Central and take full advantage of:}

- Convenient online submission

- Thorough peer review

- No space constraints or color figure charges

- Immediate publication on acceptance

- Inclusion in PubMed, CAS, Scopus and Google Scholar

- Research which is freely available for redistribution 